\title{
BMJ Open Prevalence and determinants of current cigarette smoking and secondhand smoking among Greek adolescents: the Global Youth Tobacco Survey (GYTS) 2013 study
}

George Rachiotis, ${ }^{1}$ Anastasia Barbouni, ${ }^{2}$ Athanasios Basagiannis, ${ }^{1}$
Antonis Katsioulis, ${ }^{1}$ Konstantinos Kostikas, ${ }^{1}$ Varvara Mouchtouri, ${ }^{1}$
Kyriakoula Merakou, ${ }^{2}$ Jenny Kremastinou, ${ }^{2}$ Christos S Hadjichristodoulou (D) ${ }^{1}$

To cite: Rachiotis G, Barbouni A, Basagiannis A, et al. Prevalence and determinants of current cigarette smoking and secondhand smoking among Greek adolescents: the Global Youth Tobacco Survey (GYTS) 2013 study. BMJ Open 2020;10:e034760. doi:10.1136/ bmjopen-2019-034760

- Prepublication history for this paper is available online. To view these files, please visit the journal online (http://dx.doi. org/10.1136/bmjopen-2019034760).

Received 04 November 2019 Revised 07 January 2020 Accepted 28 January 2020

\section{Check for updates}

(c) Author(s) (or their employer(s)) 2020. Re-use permitted under CC BY-NC. No commercial re-use. See rights and permissions. Published by BMJ.

${ }^{1}$ Department of Hygiene and Epidemiology, University of Thessaly Faculty of Medicine, Larissa, Greece

${ }^{2}$ Department of Public and Administrative Hygiene, National School of Public Health, Athens, Greece

Correspondence to

Dr Christos S Hadjichristodoulou; xhatzi@med.uth.gr

\section{ABSTRACT}

Objectives Smoking prevalence in Greece is considered high within the European Union and the collection of evidence on tobacco use among adolescents is of vital importance in order to develop effective smoking prevention and cessation programmes.

Design Cross-sectional.

Primary and secondary outcome measures Global Youth Tobacco Survey (GYTS) is a national representative, paper-and-pencil, cross-sectional, school-based study of students at ages 13-15 years. The survey employed a multistage cluster sample design with schools selected proportional to enrolment size. Finally, 4618/5127 students aged 13-15 years participated in the survey. The school response rate was $98.1 \%$, the student response rate was $90.1 \%$ and the overall response rate was $88.4 \%$.

Results The prevalence of current cigarette smoking was estimated at $10.1 \%$ (10.4\% in GYTS 2005) and of exposure to secondhand smoking in public places at $67.4 \%$ (94.1\% in GYTS 2005). The vast majority of the adolescents $(82.1 \%)$ supported the banning of smoking inside enclosed public places. Most of the current smokers (90.8\%) were not prevented/refused purchase because of their age according to existing law. Multivariate analysis showed that peer influence $(0 \mathrm{R}=48.32 ; 95 \% \mathrm{Cl} 36.2$ to 64.48), pocket money ( $\mathrm{OR}=2.63 ; 95 \% \mathrm{Cl} 1.28$ to 3.41$)$, increasing age $(\mathrm{OR}=2.35 ; 95 \% \mathrm{Cl} 1.63$ to 3.39$)$ and low educational level of father ( $\mathrm{OR}=2.82 ; 95 \% \mathrm{Cl} 1.7$ to 4.68$)$ were risk factors independently associated with current cigarette smoking.

Conclusions Despite the existence of strict laws related to tobacco control, exposure to secondhand smoking among Greek students remained high even when compared with GYTS in 2005. This is likely a result of weak enforcement, what is really missing is the enforcement of the related legislation.

\section{INTRODUCTION}

Tobacco cigarette smoking is the dominant form of tobacco use and a major preventable
Setting Greece.
Strengths and limitations of this study

- Nationwide, representative sample of Greek student population aged 13-15 years old.

- Standardised methodology to ensure comparability across countries.

- The questionnaires were collected through interviews resulting in satisfactory response rate.

- The main limitation of the study is related to the selfreported nature of the information collected.

hazard to human health. The WHO reported that more than 8 million deaths per year are attributed to tobacco smoking. ${ }^{1}$ It is well known that the vast majority of current adult smokers initiated smoking before the age of 18 years. ${ }^{2}$ In this context, cigarette smokingthe most prevalent form of tobacco use-has been described as a 'pediatric epidemic'. ${ }^{3}$ In addition, early initiation of smoking is associated with increased likelihood of chronic health conditions. ${ }^{4}$ In May 2003, the WHO adopted the Framework Convention on Tobacco Control (FCTC). The Global Tobacco Surveillance System (GTSS) was established in 1998 in order to establish tobacco control surveillance and monitoring programmes. ${ }^{5}$ Global Youth Tobacco Survey (GYTS) is a component of GTSS, and was developed in order to provide an international protocol for standardised monitoring and surveillance of tobacco use among adolescents. The GYTS is a joint project between WHO, US Centers for Disease Control and Prevention (CDC) and the Canadian Public Health Association. The first wave of GYTS was conducted in 140 countries and recently, the CDC analysed GYTS data from the second wave of GYTS with 61 participating countries 


\begin{tabular}{|c|c|c|}
\hline \multirow[b]{2}{*}{ Variable } & \multirow{2}{*}{$\begin{array}{l}2013 \\
\%(95 \% \mathrm{Cl})\end{array}$} & \multirow{2}{*}{$\begin{array}{l}2005 \\
\%(95 \% \mathrm{Cl})\end{array}$} \\
\hline & & \\
\hline $\begin{array}{l}\text { Current use of any tobacco } \\
\text { product }\end{array}$ & $\begin{array}{l}16.0 \\
(13.9 \text { to } 18.3)\end{array}$ & $\begin{array}{l}16.2 \\
(14.3 \text { to } 18.4)\end{array}$ \\
\hline Current cigarette smokers & $\begin{array}{l}10.1 \\
\text { (8.3 to } 12.2)\end{array}$ & $\begin{array}{l}10.4 \\
\text { (8.8 to 12.4) }\end{array}$ \\
\hline \multicolumn{3}{|l|}{ Exposure to secondhand smoke } \\
\hline At home & $\begin{array}{l}70.0 \\
(67.7 \text { to } 72.2)\end{array}$ & $\begin{array}{l}89.8 \\
(88.3 \text { to } 91.1)\end{array}$ \\
\hline In public places & $\begin{array}{l}67.4 \\
(65.2 \text { to } 69.6)\end{array}$ & $\begin{array}{l}94.1 \\
\text { (93.2 to } 94.9)\end{array}$ \\
\hline $\begin{array}{l}\text { In favour of banning smoking } \\
\text { inside enclosed public places }\end{array}$ & $\begin{array}{l}82.1 \\
\text { (79.7 to } 84.2)\end{array}$ & $\begin{array}{l}84.8 \\
\text { (82.7 to } 86.6)\end{array}$ \\
\hline $\begin{array}{l}\text { Percentage of current cigarette } \\
\text { smokers who bought cigarettes } \\
\text { and were not prevented/refused } \\
\text { purchase because of their age* }\end{array}$ & $\begin{array}{l}90.8 \\
\text { (85.2 to } 94.4)\end{array}$ & $\begin{array}{l}95.0 \\
\text { (89.5 to } 97.7)\end{array}$ \\
\hline
\end{tabular}

${ }^{*}$ From a store, shop, and so on.

across the six WHO regions for the period 2012-2015. ${ }^{6-8}$ Greece is a major tobacco-producing country within the European Union and the collection of evidence on tobacco use among adolescents is of vital importance in order to develop effective smoking prevention and cessation programmes. ${ }^{9}$ The first GYTS in Greece has been conducted in 2005. The results of this study showed that the prevalence of current tobacco use was $16.2 \%$ while the prevalence of exposure to secondhand smoke (SHS) varied from $88 \%$ at home to $93.4 \%$ in public places. ${ }^{10}$ In addition, further analysis indicated that current and secondhand smoking were influenced by several variables related to individual/social context. ${ }^{11}{ }^{12}$ The aim of the present study which uses data from the 2013 Greece GYTS was to report on the prevalence and determinants of current and secondhand smoking among Greek adolescents and compare the results of the present study to those of the first GYTS study conducted in 2005. Lastly, we examined the level of exposure to secondhand smoking and sales of tobacco products to minors in relation to the articles 8 and 16 of FCTC. ${ }^{13}$

\section{METHODS}

GYTS is a national representative, paper-and-pencil, cross-sectional, school-based study of students at ages 13-15 years. The study is based on a standardised methodology that facilitates cross-country comparisons. GYTS 2013 has been implemented by the National School of Public Health and the Department of Hygiene and Epidemiology, Medical Faculty, School of Health Sciences of the University of Thessaly.

\section{Questionnaire}

The questionnaire used included the following sections: use of tobacco products, exposure to SHS, smoking cessation, advertisements in the media for and against smoking, availability and access to tobacco products and knowledge of the harmful effects of tobacco use. Current tobacco smoking was defined as answering $\geq 1$ day to the question: 'During the past 30 days, on how many days did you smoke cigarettes?' We used three questions to assess secondhand exposure at home: (1) 'During the past 7 days, on how many days of those has anyone smoked inside your home, in your presence?' (2) 'How often do you see your father (stepfather or mother's partner) smoking in your home?' (3) 'How often do you see your mother (stepmother or father's partner) smoking in your home?' Participants who gave positive responses to at least one of the questions mentioned above were considered to have been exposed to SHS at home. We also used one question to assess secondhand exposure in public enclosed places: 'During the past 7 days, on how many days has anyone smoked in your presence, inside any enclosed public place, other than your home (school, shops, restaurants, shopping malls, movie theaters)?' Those who responded ' 0 days' were considered to have not been exposed to SHS in public places. Participants who responded '1-7 days' were considered to have been exposed to SHS in public places.

\section{Sampling}

The survey employed a multistage (geographical) cluster sample design with schools selected proportional to enrolment size. The sampling technique included two geographical strata: the Attica region and the rest of Greece. The primary sampling units were 30 high schools from each stratum. The selection of classes within the schools was based on a simple random sampling method. The final sampling units consisted of all students in the selected classes. All students in the selected classes attending school on the day of the survey were eligible to participate in the study. Parents were notified by a letter and students gave verbal consent to participate in the study.

\section{Statistical analysis}

A weighting factor was used in the analysis to reflect the likelihood of sampling each student and to reduce bias by compensating for differing patterns of non-response. The weight used for estimation is given by the following formula:

$$
\mathrm{W}=\mathrm{W} 1 * \mathrm{~W} 2 * \mathrm{f} 1 * \mathrm{f} 2 * \mathrm{f} 3 * \mathrm{f} 4
$$

where $\mathrm{W} 1$ is the inverse of the probability of selecting the school; W2 is the inverse of the probability of selecting the classroom within the school; f1 is a school-level nonresponse adjustment factor calculated by school size category (small, medium, large); f2 is a class-level nonresponse adjustment factor calculated for each school; f3 is a student-level non-response adjustment factor calculated by class; and $\mathrm{f} 4$ is a poststratification adjustment 
Table 2 Univariate analysis of current cigarette smoking, GYTS Greece 2013

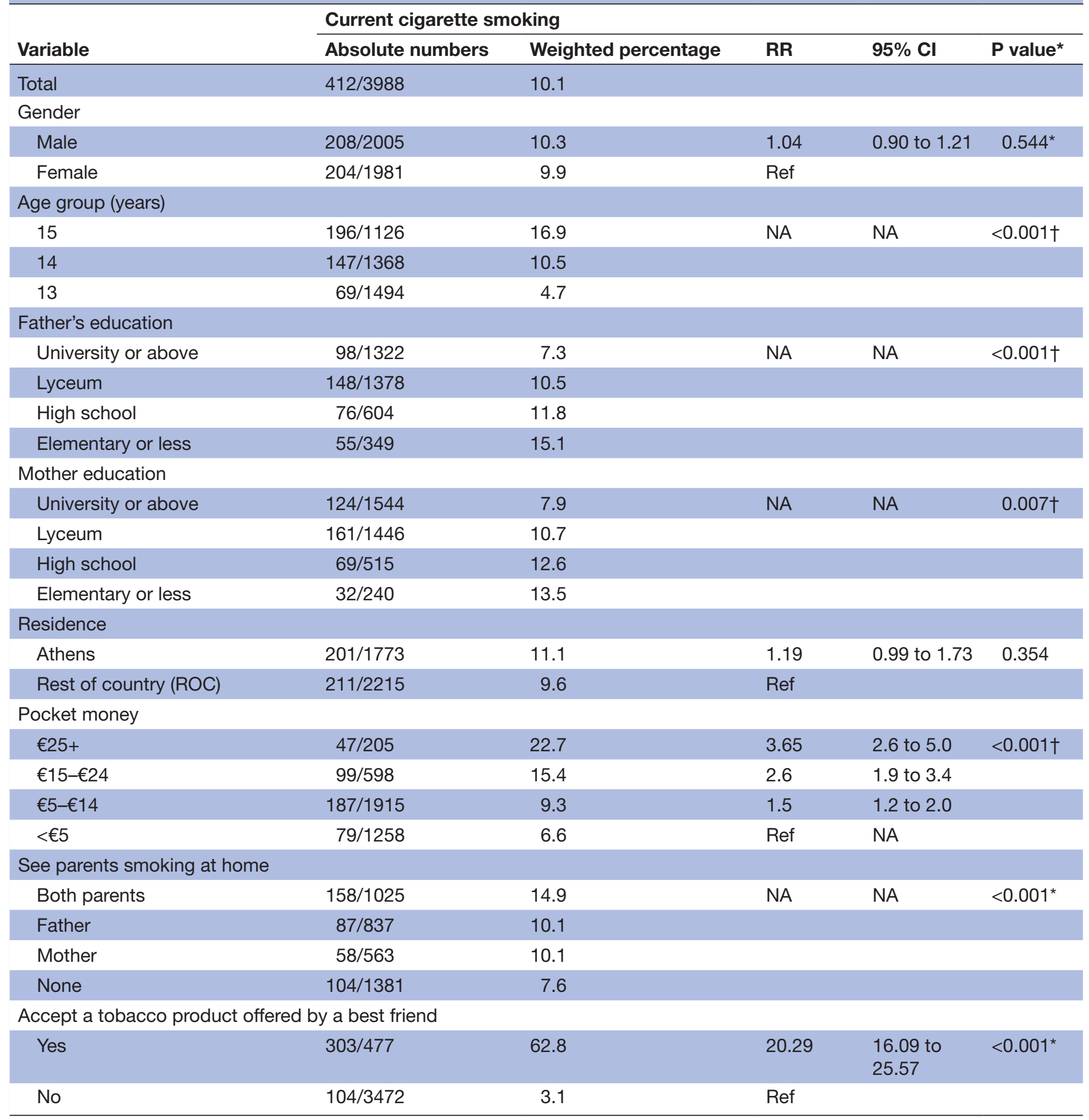

${ }^{*}$ Pearson's $\chi^{2}$ test.

$+\chi^{2}$ test for trend.

GYTS, Global Youth Tobacco Survey; NA, not applicable; RR, relative risk.

factor calculated by grade. In univariate analysis, Pearson's $\chi^{2}$ test was used to analyse associations between sociodemographic factors and current and secondhand smoking. Relative risk with their corresponding 95\% CIs was also calculated. $\chi^{2}$ test for trend was used to determine whether the proportion of current smoking differed significantly across age, parents' education and pocket money subgroups. In multivariate analysis, logistic regression analysis was employed to identify independent risk factors for the current and secondhand smoking. ORs and $95 \%$ CI were calculated. $\mathrm{P}$ values were considered statistically significant if $\mathrm{p}<0.05$. All analyses were performed using the complex sample module of SPSS V.19.0. 
Table 3 Multivariate analysis of current cigarette smoking, GYTS Greece 2013

\begin{tabular}{|c|c|c|c|}
\hline \multirow[b]{2}{*}{ Variable } & \multicolumn{3}{|c|}{ Current cigarette smoking } \\
\hline & OR & $95 \% \mathrm{Cl}$ & $P$ value \\
\hline \multicolumn{4}{|l|}{ Gender } \\
\hline Male & 1.25 & 0.96 to 1.62 & 0.089 \\
\hline Female & Ref & & \\
\hline \multicolumn{4}{|l|}{ Age group (years) } \\
\hline 15 & 2.35 & 1.63 to 3.39 & $<0.001$ \\
\hline 14 & 1.73 & 1.20 to 2.48 & 0.004 \\
\hline 13 & Ref & & \\
\hline \multicolumn{4}{|l|}{ Father's education } \\
\hline University or above & Ref & & \\
\hline Lyceum & 1.45 & 1.03 to 2.05 & 0.034 \\
\hline High school & 1.56 & 0.97 to 2.52 & 0.068 \\
\hline Elementary or less & 2.82 & 1.7 to 4.68 & $<0.001$ \\
\hline \multicolumn{4}{|l|}{ Pocket money } \\
\hline$€ 25+$ & 2.63 & 1.28 to 5.41 & 0.010 \\
\hline$€ 15-€ 24$ & 1.84 & 1.18 to 2.86 & 0.009 \\
\hline$€ 5-€ 14$ & 1.54 & 0.94 to 2.50 & 0.082 \\
\hline$<€ 5$ & Ref & & \\
\hline \multicolumn{4}{|c|}{ Accept a tobacco product offered by a best friend } \\
\hline Yes & 48.32 & 36.22 to 64.48 & $<0.001$ \\
\hline No & Ref & & \\
\hline
\end{tabular}

GYTS, Global Youth Tobacco Survey.

Patient and public involvement

No patient and public were involved in this study.

\section{RESULTS}

Finally, 4618/5127 students aged 13-15 years participated in the survey. The school response rate was $98.1 \%$, the student response rate was $90.1 \%$ and the overall response rate was $88.4 \%$.

Table 1 presents the evolution of the prevalence of a set of smoking-related variables in 2005 (first GYTS in Greece) and 2013 (second GYTS in Greece). The prevalence of current cigarette smoking was $10.1 \%$ compared with $10.4 \%$ in 2005 . With respect to secondhand smoking at home the environmental tobacco smoke (ETS) exposure was reduced from $89.8 \%$ in 2005 to $56.7 \%$ in 2013 . The prevalence of exposure to secondhand smoking in public places decreased from $94.1 \%$ in 2005 to $67.4 \%$ in 2013. With respect to the intensity of exposure to SHS in enclosed public places, $27.1 \%$ of the participants reported exposure to SHS for 1-2 days per week, $15 \%$ for 3-4 days/week, $7.3 \%$ for 5-6 days per week and $17.9 \%$ for 7 days per week. The vast majority of the adolescents supported the banning of smoking inside enclosed public places $(84.8 \%$ in 2005 vs $82.1 \%$ in 2013 ). The percentage of current cigarette smokers who bought cigarettes and were not prevented/refused purchase because of their age decreased from $95 \%$ in 2005 to $90.8 \%$ in 2013.

The results of the univariate analysis of current cigarette smoking appear in table 2. These results suggest a doseresponse relationship between pocket money and current cigarette smoking. Multivariate analysis (table 3) showed that peer influence $(\mathrm{OR}=48.32 ; 95 \% \mathrm{CI} 36.22$ to 64.48$)$, pocket money $(\mathrm{OR}=2.63 ; 95 \%$ CI 1.28 to 5.41$)$, increasing age $(\mathrm{OR}=2.35 ; 95 \% \mathrm{CI} 1.63$ to 3.39$)$ and low educational level of father (OR=2.82; 95\% CI 1.70 to 4.68$)$ for elementary or less compared with the university were risk factors independently associated with current cigarette smoking. Table 4 reports the results of univariate analysis of secondhand smoking exposure. Multivariate analysis indicated that female gender $(\mathrm{OR}=1.00$ compared with 0.60 for males; $95 \%$ CI 0.51 to 0.71$)$, increasing age ( $\mathrm{OR}=1.78 ; 95 \%$ CI 1.44 to 2.19), pocket money (€15-€24 per week compared with $<€ 5$ per week; OR=2.36; 95\% CI 1.78 to 3.12), parental (both parents) smoking at home $(\mathrm{OR}=2.86 ; 95 \%$ CI 2.28 to $3.58)$ and peer influence (OR=1.85; $95 \%$ CI 1.26 to 2.71) were independently associated with the likelihood of exposure to SHS (table 5).

\section{DISCUSSION}

The results from the second wave of GYTS study in Greece raise several major points over the state of tobacco control among Greek adolescents aged 13-15 years. The prevalence of current cigarette smoking among adolescents was estimated at 10.1 in $2013 \%$ compared with $10.4 \%$ in 2005. A comparison of GYTS national prevalence survey results within the European Region of WHO indicates that Greece recorded lower current smoking prevalence compared with Italy $(23.4 \%)$, Latvia $(16.8 \%)$ and Lithuania $(19.4 \%)$ but higher than Romania (9.4\%), Moldova $(7.2 \%)$ and Montenegro $(6.9 \%){ }^{7}$ With respect to current smoking determinants the Greece 2013 GYTS showed that peer influence, higher amount of pocket money, father's level of education and increasing age were independent determinants of current cigarette smoking. The strongest determinant of current smoking was peer influence. This finding is in line with previous research. ${ }^{11}$ In particular, individuals tend to socially compare their own self-image with their prototype of the 'ideal' person (eg, close friend, parent) engaging in various hazardous behaviours. ${ }^{14}$ Nevertheless, we would like to note that it is methodologically challenging to separate the impact of peer influence from selection effects given that students choose friends who have smoking behaviours similar to their own.

Availability of pocket money proved also to be a strong risk factor independently associated with the likelihood of current smoking. This finding is consisted with previous GYTS results from Cyprus ${ }^{15}$ and Greece ${ }^{11}$ and has important public health implications. In particular, parents who hand over pocket money to adolescents should take into consideration how that pocket money is used. Furthermore, the role of pocket money as a risk factor for current smoking should be considered in 
Table 4 Univariate analysis of secondhand smoking, GYTS Greece 2013

Secondhand smoke in enclosed public places in the past 7 days

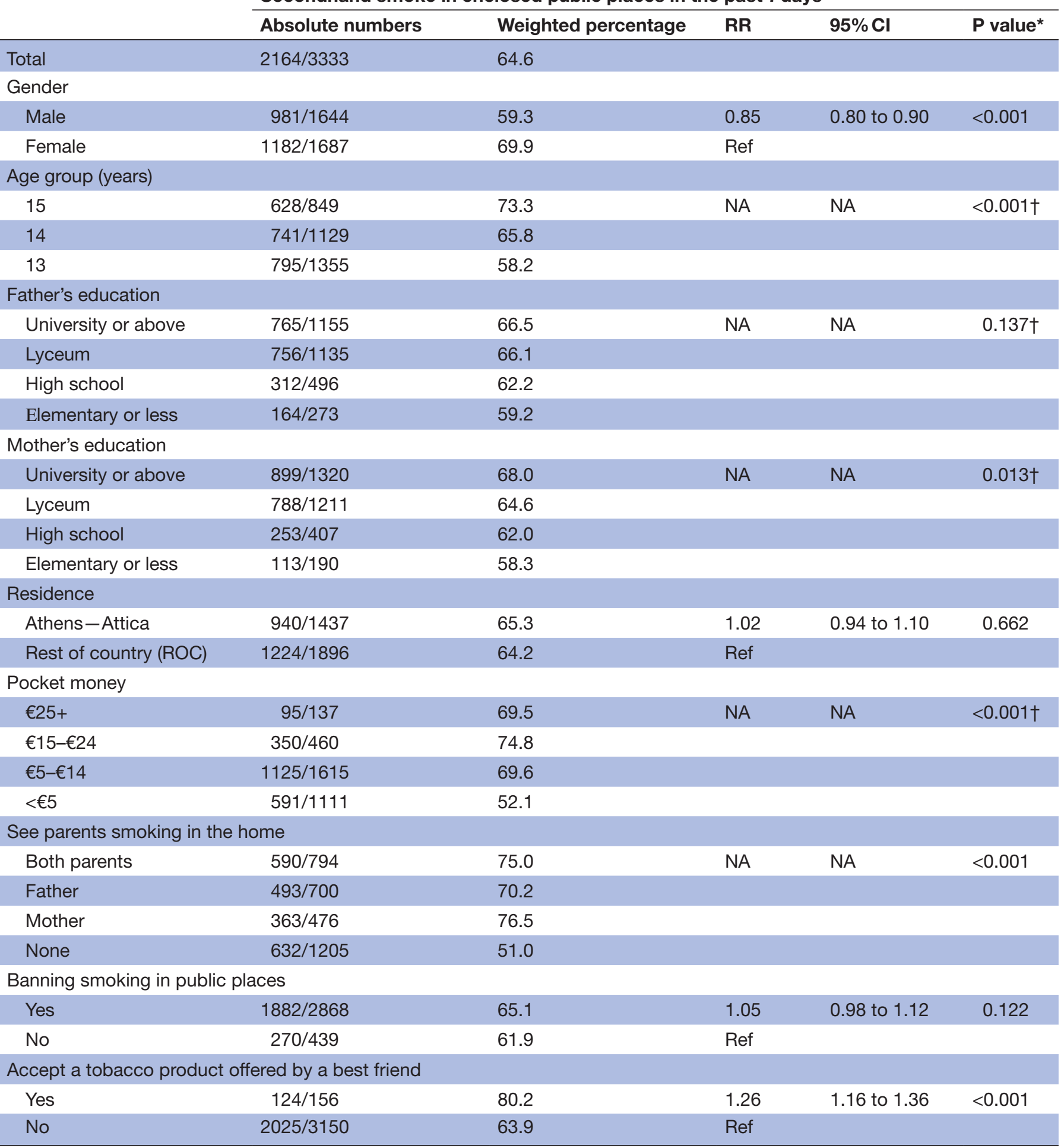

${ }^{*} \chi^{2}$ test for trend.

†Pearson's $\chi^{2}$ test.

GYTS, Global Youth Tobacco Survey; NA, not applicable; RR, relative risk.

conjunction with adolescents' easy access to cigarettes in spite of existing law prohibiting the sale of cigarettes to minors. Greater enforcement of laws banning the retail sale of tobacco products to minors in other countries such as the USA has yielded higher rates of adolescents reporting retailer refusals than observed among respondents here. Enforcement efforts that have worked elsewhere and may work in Greece include licensing tobacco 
Table 5 Multivariate analysis of secondhand smoking, GYTS Greece 2013

\begin{tabular}{|c|c|c|c|}
\hline & \multicolumn{3}{|c|}{$\begin{array}{l}\text { Exposure to secondhand smoke in } \\
\text { enclosed public places in the past } 7 \text { days }\end{array}$} \\
\hline & OR & $95 \% \mathrm{Cl}$ & P value \\
\hline \multicolumn{4}{|l|}{ Gender } \\
\hline Male & 0.60 & 0.51 to 0.71 & $<0.001$ \\
\hline Female & Ref & & \\
\hline \multicolumn{4}{|l|}{ Age (years) } \\
\hline 15 & 1.78 & 1.44 to 2.19 & $<0.001$ \\
\hline 14 & 1.36 & 1.12 to 1.66 & 0.004 \\
\hline 13 & Ref & & \\
\hline \multicolumn{4}{|l|}{ Pocket money } \\
\hline$€ 25+$ & 1.98 & 1.03 to 3.82 & 0.041 \\
\hline$€ 15-€ 24$ & 2.36 & 1.78 to 3.12 & $<0.001$ \\
\hline$€ 5-€ 14$ & 1.93 & 1.58 to 2.36 & $<0.001$ \\
\hline$<€ 5$ & Ref & & \\
\hline \multicolumn{4}{|c|}{ See parents smoking in the home } \\
\hline Both parents & 2.86 & 2.28 to 3.58 & $<0.001$ \\
\hline Father & 2.33 & 1.77 to 3.08 & $<0.001$ \\
\hline Mother & 3.08 & 2.29 to 4.15 & $<0.001$ \\
\hline None & Ref & & \\
\hline \multicolumn{4}{|c|}{ Accept a tobacco product offered by a best friend } \\
\hline Yes & 1.85 & 1.26 to 2.71 & 0.003 \\
\hline No & Ref & & \\
\hline
\end{tabular}

GYTS, Global Youth Tobacco Survey.

retailers and cancelling their licence if undercover inspections reveal violations. An additional deterrent found effective in many countries would be the imposition of excise taxes on cigarettes. Given the evidence that substantial weekly pocket money facilitates tobacco use among youth, increasing the cost of cigarettes by imposing an excise tax on cigarettes would discourage their tobacco use. In addition, increased monitoring of sales outlets should be considered. We found no gender difference with regard to current smoking. This finding may reflect changes in the gender-related prevalence of current smoking during the period 2005-2013. Indeed, the prevalence of current smoking among females has been increased from $9 \%$ in 2005 to $9.9 \%$ in 2013 . In addition the prevalence of current smoking among males has been decreased from $11.3 \%$ in 2005 to 10.3 in 2013 . In contrast, we found that males were less likely to be exposed to ETS in enclosed public places compared with females. This result was in line with our previous findings from $2005 .{ }^{12}$

The exposure of Greek students to SHS remains extremely high and this is the case for both home $(56.7 \%)$ and enclosed public places $(67.4 \%)$. We have also noted a high intensity of exposure to SHS in public places. In particular, $40.3 \%$ of the adolescents reported exposure to SHS 3-7 days per week. Especially for enclosed public places it is of note that we found a considerable decrease in exposure to SHS in comparison to the results of the first wave of GYTS in Greece in 2005. This finding is in line with the reported significant reduction of particulate matter levels following the complete ban of smoking in hospitality venues. ${ }^{16}$ However, the existing levels of exposure to ETS are still high and not in compliance with article 8 of the WHO FCTC which highlights the importance of protection from exposure to tobacco smoke. It is also well known that ETS has been classified by the International Agency for Research on Cancer as a human carcinogen. ${ }^{17}$ We believe that the high level of exposure to ETS reflects the absence of political will of subsequent Greek governments to impose the regulatory control of the smoking ban legislation. Moreover, it should be underlined that tobacco industry has claimed that enforcement of smoke-free laws caused hospitality revenues to decline considerably. However, accumulated, high-quality evidence indicates that these claims are unfounded. ${ }^{18}$ In addition, it should be taken into account that the vast majority of students $(82 \%)$ supported the smoking ban in enclosed public places.

Despite the existing legislation which prohibits the sale of tobacco to minors we found that the vast majority $(90.8 \%$ vs $95 \%$ in 2005) of current smokers had access to cigarettes and were not prevented/refused purchase because of their age. Greece has ratified FCTC and the article 16 of this WHO Framework Convention recommends that signatories prohibit the sale of tobacco to minors. This recommendation has been made on the bases of scientific evidence suggesting that disruption of the commercial distribution of tobacco to youth results in reduction of smoking rates among adolescents. Our data clearly demonstrate that the implementation of the legislation related to the article 16 of the FCTC in Greece is not satisfactory.

Our results are subject to several limitations. First, data were based on self-reports, which might result in information bias related to misclassification of smoking use. ${ }^{19}$ There is some evidence that the use of questionnaires for the evaluation of smoking use has low sensitivity and thus an underestimation of smoking use is expected. ${ }^{19}$ Second, the data presented represent only youths who are enrolled in school, which might limit generalisability to all youths aged 13-15 years in Greece. However, the majority of Greek adolescents between the ages 13 and 15 usually attend the high school since it is obligatory according to the law. High student dropout is expected only for disadvantaged social groups (eg, Roma). Moreover, according to the European Commission, Greece has a low student dropout rate $(<10 \%)$ in the European Union. ${ }^{20}$ Third, we were not able to get data from non-responders and thus selection bias may have occurred. On the other hand, we believe that the sampling method employed reduced considerably the risk of selection bias. Moreover, the use of a standardised data collection protocol to collect the questionnaire-based data would have likely minimised the risk of information bias. We have already acknowledged limitation related to inverse causality with respect to the 
impact of selection effects on peer influence given that student choose friends who have smoking behaviours similar to their own. ${ }^{21}$ Last, our study has the advantage of the use of a standardised questionnaire that enables cross-country comparisons of smoking use.

In conclusion, the present study demonstrated that current smoking rates among Greek students aged 13-15 years old remained almost stable in comparison to the first wave of GYTS study in 2005. It is also of note that despite the laws that prohibit the access of minors to tobacco, our results indicate that smoking ban laws are not being upheld. Consequently, the exposure of youths to SHS in Greece can be considered as an uncontrolled hazard. Our policy recommendations include for the Greek government to ensure the urgent enforcement of the antismoking ban legislation in enclosed public places and also of the law which prohibits the sale of tobacco to minors.

Acknowledgements We acknowledge the medical students, K loannides, G Perifanos, V Akrivos, G Hasiotis, EA Politaki, V Flega, D Exarchopoulou, AK Papadopoulou, AA Menis, Z Diakonikolaou, E Agianni and Dr G Toulios, for their help with this study.

Contributors GR participated in study design, and drafted and revised the manuscript. $A B$ participated in study design, supervised the study implementation and revised the manuscript. $A B$ participated in collection of data and revision of the manuscript. AK participated in study design and statistical analysis. KK participated in study design and revision of the manuscript. VM interpreted the results and revised the manuscript. KM participated in study design and revised the manuscript. JK participated in study design and revised the manuscript for important intellectual content. CSH supervised the study design and the implementation of the study, and participated in statistical analysis, interpretation of results and revision of the manuscript. All authors have read and approved the final version of the manuscript.

Funding The GYTS Greece 2013 is implemented through the Operational Programme entitled 'Human Resources Development' of National Strategic Reference Framework (NSRF) 2007-2013. The programme was cofunded by Greece and the European Union-European Regional Development Fund. Chronic Disease Prevention and Health Promotion and the US Centers for Disease Control and Prevention (CDC) provided technical assistance.

Competing interests None declared.

Patient consent for publication Not required.

Ethics approval The protocol of the study has been approved by the Ministry of National Education and Religions, Athens, Greece (ID: 41996/Г2/6-4-2011 and 41996/Г2/31-5-2012).

Provenance and peer review Not commissioned; externally peer reviewed.

Data availability statement Data are available in a public, open access repository (https://extranet.who.int/ncdsmicrodata/index.php/catalog/539/data_dictionary).

Open access This is an open access article distributed in accordance with the Creative Commons Attribution Non Commercial (CC BY-NC 4.0) license, which permits others to distribute, remix, adapt, build upon this work non-commercially, and license their derivative works on different terms, provided the original work is properly cited, appropriate credit is given, any changes made indicated, and the use is non-commercial. See: http://creativecommons.org/licenses/by-nc/4.0/.

ORCID iD

Christos S Hadjichristodoulou http://orcid.org/0000-0002-4769-8376
REFERENCES

1 World Health Organization. Tobacco. Available: https://www.who.int/ health-topics/tobacco [Accessed 6 Jan 2019].

2 Substance Abuse and Mental Health Services Administration (SAMHSA). Tobacco. Available: https://www.samhsa.gov/atod/ tobacco [Accessed 10 Jan 2019].

3 Perry CL, Eriksen M, Giovino G. Tobacco use: a pediatric epidemic. Tob Control 1994;3:97-8.

4 Committee on the Public Health Implications of Raising the Minimum Age for Purchasing Tobacco Products, Board on Population Health and Public Health Practice, Institute of Medicine, Bonnie RJ, Stratton $\mathrm{K}$, Kwan LY, eds. Public health implications of raising the minimum age of legal access to tobacco products. Washington, DC: National Academies Press (US), 2015.

5 World Health Organization. WHO framework convention on. Geneva: Tobacco Control, 2003. http://www.who.int/tobacco/framework/ WHO_FCTC_english.pdf

6 Warren CW, Jones NR, Peruga A, et al. Global youth tobacco surveillance, 2000-2007. MMWR Surveill Summ 2008;57:1-21.

7 D'Angelo D, Ahluwalia IB, Pun E, et al. Current Cigarette Smoking, Access, and Purchases from Retail Outlets Among Students Aged 13-15 Years - Global Youth Tobacco Survey, 45 Countries, 2013 and 2014. MMWR Morb Mortal Wkly Rep 2016;65:898-901.

8 Arrazola RA, Ahluwalia IB, Pun E, et al. Current Tobacco Smoking and Desire to Quit Smoking Among Students Aged 13-15 Years Global Youth Tobacco Survey, 61 Countries, 2012-2015. MMWR Morb Mortal Wkly Rep 2017;66:533-7.

9 The Tobacco Atlas. Greece. Available: https://tobaccoatlas.org/ country/greece/

10 Kyrlesi A, Soteriades ES, Warren CW, et al. Tobacco use among students aged 13-15 years in Greece: the GYTS project. BMC Public Health 2007;7:3.

11 Rachiotis G, Muula AS, Rudatsikira E, et al. Factors associated with adolescent cigarette smoking in Greece: results from a cross sectional study (GYTS study). BMC Public Health 2008;8:313.

12 Rachiotis G, Siziya S, Muula AS, et al. Determinants of exposure to environmental tobacco smoke (ETS) among non smoking adolescents (aged 11-17 years old) in Greece: results from the 2004-2005 GYTS study. Int J Environ Res Public Health 2010;7:284-90.

13 Usmanova G, Mokdad AH. Results of the global youth tobacco survey and implementation of the WHO framework convention on tobacco control in the WHO eastern Mediterranean region (EMR) countries. J Epidemiol Glob Health 2013;3:217-34.

14 Blanton H, Gibbons FX, Gerrard M, et al. Role of family and peers in the development of prototypes associated with substance use. $J$ Fam Psychol 1997;11:271-88.

15 Christophi CA, Savvides ECG, Warren CW, et al. Main determinants of cigarette smoking in youth based on the 2006 Cyprus GYTS. Prev Med 2009;48:232-6.

16 Vardavas Cl, Anagnostopoulos N, Patelarou E, et al. Five-Year trends of second-hand smoke exposure in Greece: a comparison between complete, partial, and prelegislation levels. J Aerosol Med Pulm Drug Deliv 2012;25:349-54.

17 IARC Working Group on the Evaluation of Carcinogenic Risks to Humans. Tobacco smoke and involuntary smoking. In: Monographs on the evaluation of carcinogenic risks to humans. 83. IARC Press: Lyon, 2004.

18 Glantz SA, Smith LR. The effect of ordinances requiring smoke-free restaurants and bars on revenues: a follow-up. Am J Public Health 1997;87:1687-93.

19 Malcon MC, Menezes AMB, Assunção MCF, et al. Agreement between self-reported smoking and cotinine concentration in adolescents: a validation study in Brazil. $J$ Adolesc Health 2008;43:226-30.

20 European Commission. European Semester thematic Factsheet. Early school leavers. Available: https://ec.europa.eu/info/sites/info/ files/european-semester_thematic-factsheet_early-school-leavers_ en_0.pdf [Accessed 6 Sep 2019].

21 Shalizi CR, Thomas AC. Homophily and contagion are generically confounded in observational social network studies. Sociol Methods Res 2011;40:211-39. 